\title{
Effective cleaning of rust stained marble
}

CrossMark

Sanne Spile ${ }^{1}$, Takayoshi Suzuki ${ }^{2}$, Jesper Bendix ${ }^{3}$ and Kim Pilkjær Simonsen ${ }^{1 *}$

\begin{abstract}
Background: Calcareous materials, like marble used in connection with cultural heritage objects such as statues and pedestals, or as wall facings on buildings, often show a brownish staining owing to contact with iron metal or ironcontaining minerals in the stone. The discolouration alters the appearance of the stone, which is undesirable from an aesthetic point of view. Despite rust staining being a conspicuous phenomenon and numerous works that have dealt with the problem of removing rust stains, a simple and non-toxic method has so far been missing. This paper describes a highly efficient method for cleaning rust stains from marble by introducing the chelating amino acid cysteine in a Laponite poultice in combination with the strong reducing agent sodium dithionite.
\end{abstract}

Results: Cleaning experiments were performed on artificially discoloured samples of various types of Carrara Bianco marble and on naturally rust stained marble. To begin with, solutions of cysteine in combination with sodium dithionite and ammonium carbonate were tested by immersion of samples into the different solutions. Secondly, solutions of cysteine and sodium dithionite with and without buffering were used in a poultice consisting of Laponite ${ }^{\circledR} \mathrm{RD}$, Arboce ${ }^{\circledR}$ BC1000 and CMC. The poultice was applied on three different marble types: Carrara Fabricotti, Carrara Vagli and Carrara La Piana. Thirdly, the optimized method was tested on original rust stained material of Greenlandic marble, which has been used as wall facing, and finally in situ in Copenhagen on a larger area of The Marble Church showing rust stains due to pyrite oxidation. The cleaning results were evaluated by visual observations, cross sections, and etching of the surface by testing on high gloss marble.

Conclusion: Cleaning of iron-discoloured marble surfaces has been investigated and a new method for removal of rust stained marble has been developed. A solution of $0.1 \mathrm{M}$ cysteine and $0.1 \mathrm{M}$ sodium dithionite in a poultice consisting of Laponite ${ }^{\circledR} \mathrm{RD} /$ Arboce $^{\circledR}{ }^{\circledR} \mathrm{BC} 1000 / \mathrm{CMC}=10: 10: 1$ has shown to be a fast, simple, cheap, and non-toxic, do-it-yourself method.

Keywords: Rust stain, Marble, Cleaning, Cysteine, Dithionite, Poultice, Laponite, Arbocel

\section{Background}

Since ancient times, white marble has been used as a popular material for sculptural artefacts such as statues, busts, and friezes as well as an architectural building material with numerous applications from flooring, wall facings, and pedestals, to columns and fountains. Although marble is a relatively stable material, the desired white surface is unfortunately prone to tarnishing when used in outdoor environments [1]. One of the major sources of tarnishing is iron. In addition to the oxidation of internal iron compounds present in stone like pyrite $\left(\mathrm{FeS}_{2}\right)$ and siderite $\left(\mathrm{FeCO}_{3}\right)[1,2]$, contact

\footnotetext{
*Correspondence: kps@kadk.dk

1 School of Conservation, Esplanaden 34, 1263 Copenhagen K, Denmark Full list of author information is available at the end of the article
}

with iron-rich ground water when marble is used in, for example, garden fountains, results in severe and unsightly discolouration [3]. Another cause is the proximity to iron metal, which is oxidized by air in the presence of rain. The solubilized ions are then transported by rain onto the marble surface, resulting in rust formation [4].

The detailed mechanism for rust formation is highly complex; depending on the $\mathrm{pH}$ value, different species, all characterized by a brownish colour, are formed. The atmospheric corrosion of iron, regardless of the $\mathrm{pH}$ value of the reaction may, however, be summarized by the overall stoichiometric reaction (1) where the product $\mathrm{FeOOH}$ represents the generic formula for rust [5].

$$
4 \mathrm{Fe}_{(\mathrm{s})}+3 \mathrm{O}_{2(\mathrm{~g})}+2 \mathrm{H}_{2} \mathrm{O}_{(\mathrm{l})} \rightarrow 4 \mathrm{FeOOH}_{(\mathrm{s})}
$$

(C) 2016 Spile et al. This article is distributed under the terms of the Creative Commons Attribution 4.0 International License (http://creativecommons.org/licenses/by/4.0/), which permits unrestricted use, distribution, and reproduction in any medium, provided you give appropriate credit to the original author(s) and the source, provide a link to the Creative Commons license, and indicate if changes were made. The Creative Commons Public Domain Dedication waiver (http://creativecommons.org/ publicdomain/zero/1.0/) applies to the data made available in this article, unless otherwise stated. 
The general name rust consists of a variety of iron(III) oxyhydroxides or hydrated oxides of high stability and low solubility. The actual species formed depend as mentioned on the $\mathrm{pH}$ value and the presence of different anions [6-8]. The thermodynamic parameters and solubility products have been estimated for many of the rust species, such as ferrihydrite and $\alpha-, \beta$ - and $\gamma-\mathrm{FeOOH}$ (goethite, akaganeite and lepidocrocite). These investigations have shown that goethite defines a thermodynamic minimum of the rust system $[7,9]$ and the solubility product of goethite $\left(\mathrm{K}_{\mathrm{sp}}=10^{-41}\right)$ is the lowest among the different rust species [7]. This means, from a thermodynamic point of view, that rust can be examined as goethite, and thus the cleaning of rust can be considered as removal of goethite.

Rust discolouration of marble is characterized by areas or stains having an orange to brownish colour, which alters the appearance of the stone. From an aesthetic point of view, the discolouration is undesirable and stone conservators and conservation scientists have therefore worked for several decades with various cleaning methods in attempts to remove rust stains from marble and calcareous stone materials [3,10-12].

Due to the nature of the discoloration and the possibility of damaging the stone, the stain can only be removed by chemical cleaning. The current method for rust cleaning involves application of different ligands and reducing agents mixed in a poultice and placed onto the stone surface. One of the ligands most widely used is the citrate ion $[10,11,13]$, though salts of other carboxylic acids, such as oxalic and tartaric acid, have also been used [10]. Other methods involve the use of fluoride [10] or EDTA [12]. A relatively new method is the use of the hexadentate ligand tpen, which, in contrast to EDTA, has a high affinity towards iron and a low affinity towards calcium [3]. This ligand has shown excellent results when tested on a discoloured marble fountain, however this method is rather expensive. The ligands are used either alone or in combination with reducing agents like thiosulfate, dithionite or polythiophene $[3,10]$. Thioglycolic acid and ammonium thioglycolate have been applied in several conservation treatments of calcareous stone [12]. Thioglycolate is presumably the most efficient ligand for cleaning rust stained marble $[12,13]$. However, thioglycolic acid is a toxic chemical, and is thus difficult to acquire for private stone conservators without access to a laboratory. In addition to this, a slightly violet colour may appear on the marble when cleaning with thioglycolic acid, which demands a second cleaning [12].

In this study, we have aimed to investigate and develop a new method for rust cleaning of discoloured marble. The focus has been on the use of cheap and commercially available chemicals. Another target was reduction of $\mathrm{Fe}(\mathrm{III})$ to $\mathrm{Fe}(\mathrm{II})$ while cleaning. Efficient removal of a slightly soluble material requires a ligand having an overall stability constant comparable to the reciprocal value of the solubility product in order to achieve a favourable equilibrium constant. Based on the solubility product of goethite, efficient removal of rust in Fe(III) stage requires a ligand having a stability constant approaching $10^{41}$, whereas removal of $\mathrm{Fe}(\mathrm{OH})_{2}$ only requires a stability constant of $10^{14}$. Additionally, the ligand should possess low affinity towards $\mathrm{Ca}$ (II) to prevent dissolution of calcite.

\section{Introducing new chemistry for rust cleaning}

In the search for an efficient method for rust cleaning, the focus has been both on a ligand showing strong complex formation with iron and weak binding to the major constituent ions in marble i.e. $\mathrm{Ca}(\mathrm{II})$ and $\mathrm{Mg}(\mathrm{II})$, as well as on the identification of a fast reducing agent able to reduce $\mathrm{Fe}(\mathrm{III})$ to $\mathrm{Fe}(\mathrm{II})$. Among the reducing chemicals, sodium dithionite (SD), $\mathrm{Na}_{2} \mathrm{~S}_{2} \mathrm{O}_{4}$, has been successfully used in combination with different ligands as a dissolving agent for goethite in soil analyses $[14,15]$ and for removal of rust from paper [16]. Furthermore, the use of dithionite in conservation science in general is well described [17].

The standard reduction potential, $\mathrm{e}^{\circ}$, of dithionite in the basic solution given in Eq. (2) has been determined to $-1.12 \mathrm{~V}$ (vs. NHE) $[15,17]$ and is thereby one of the strongest reducing agents among the simple, cheap, commercial reagents. The reducing power decreases with lower $\mathrm{pH}$ values and using $\mathrm{pK}_{\mathrm{a} 2}=7$ for hydrogen sulphite the potential can be calculated to $\mathrm{e}^{\circ /}=-0.29 \mathrm{~V}$ at $\mathrm{pH}=7$.

$2 \mathrm{HSO}_{3}^{-}+2 \mathrm{H}^{+}+2 \mathrm{e}^{-} \rightleftarrows \mathrm{S}_{2} \mathrm{O}_{4}^{2-}+2 \mathrm{H}_{2} \mathrm{O} \quad \mathrm{e}^{\circ \prime}=-0.29 \mathrm{~V}$

In aqueous solution dithionite partly dissociates, forming the highly reactive monomeric sulphur dioxide radical anion with the dissociation equilibrium constant $\mathrm{K}=10^{-9}[18]$.

$$
\mathrm{S}_{2} \mathrm{O}_{4}^{2-} \rightleftarrows 2 \mathrm{SO}_{2}^{--}
$$

Even though the amount of the radical anion is relatively small and can be estimated to $10^{-5} \mathrm{M}$ in a $0.1 \mathrm{M}$ dithionite solution, the anion has shown to be the dominant reducing species in the reduction and dissolution of iron oxides [14, 15]. From biochemical experiments, the standard reduction potential of the radical anion has been determined to $-1.39 \mathrm{~V}$ (vs. NHE) in basic solution $[18,19]$, giving a calculated value $\mathrm{e}^{\circ /}=-0.56 \mathrm{~V}$ at $\mathrm{pH}=7$ in accordance with experimentally determined values [18].

$\mathrm{HSO}_{3}^{-}+\mathrm{H}^{+}+\mathrm{e}^{-} \rightleftarrows \mathrm{SO}_{2}^{--}+\mathrm{H}_{2} \mathrm{O} \quad \mathrm{e}^{\mathrm{o}}=-0.56 \mathrm{~V}$ 
The reduction potential for reduction and dissolution of synthetic goethite has been calculated to $\mathrm{e}^{\circ \prime}=-0.14 \mathrm{~V}$ (vs. NHE) at $\mathrm{pH}=7$ [20]. Using this value and either dithionite or the sulfur dioxide radical anion in the reduction and dissolution of goethite to $\mathrm{Fe}(\mathrm{II})$, the reactions can be written as in Eqs. (5), (6) with the electrochemical potentials of $\mathrm{E}^{\circ \prime}=+0.15 \mathrm{~V}$ or $\mathrm{E}^{\circ \prime}=+0.42 \mathrm{~V}$.

$$
\begin{gathered}
2 \mathrm{FeOOH}_{(\mathrm{s})}+\mathrm{S}_{2} \mathrm{O}_{4}^{2-}+4 \mathrm{H}^{+} \rightleftarrows 2 \mathrm{Fe}^{2+} \\
+2 \mathrm{HSO}_{3}^{-}+2 \mathrm{H}_{2} \mathrm{O} \quad \mathrm{E}^{\mathrm{o}}=+0.15 \mathrm{~V} \\
\mathrm{FeOOH}_{(\mathrm{s})}+\mathrm{SO}_{2}^{--}+2 \mathrm{H}^{+} \rightleftarrows \mathrm{Fe}^{2+} \\
+\mathrm{HSO}_{3}^{-}+\mathrm{H}_{2} \mathrm{O} \quad \mathrm{E}^{\mathrm{O} \prime}=+0.42 \mathrm{~V}
\end{gathered}
$$

Both reactions are spontaneous processes with relatively large equilibrium constants, which can be calculated to $\mathrm{K}=10^{5}$ or $\mathrm{K}=10^{7}$, respectively. From a thermodynamic point of view, dissolution of rust could be achieved by SD solutions only. However, the presence of a ligand for removal of the $\mathrm{Fe}(\mathrm{II})$ ions is preferable in order to avoid re-precipitation caused by oxidation from oxygen.

In search of a ligand useful for rust removal, a sulphide-containing species similar to thioglycolate were examined. The amino acid cysteine (cys), commonly found in natural proteins as the L-isomer, is commercially available and affordable. Cysteine forms complexes with $\mathrm{Fe}(\mathrm{III})$ and $\mathrm{Fe}(\mathrm{II})$ with high stability constants and only very weak complexes with $\mathrm{Ca}(\mathrm{II})$ and $\mathrm{Mg}$ (II) [21]. At the same time cysteine reacts as a reducing agent in the iron(III)-cysteine complexes with formation of colourless $\mathrm{Fe}(\mathrm{II})$-cysteine complexes [22]. The intense violet colour known for $\mathrm{Fe}$ (III) complexes with ligands containing thiol groups like cys and thioglycolate [12, 22] may therefore be avoided. In addition to this, cys is also able to perform reductive dissolution of iron(III) oxyhydroxides, thereby independently having a solubilizing effect of rust [23].

Table 1 shows the stability constants of the marble constituents $\mathrm{Ca}(\mathrm{II}), \mathrm{Mg}(\mathrm{II}), \mathrm{Fe}(\mathrm{II})$ and $\mathrm{Fe}(\mathrm{III})$, with the commonly used ligands for rust cleaning i.e. citrate [24], oxalate [24], tartrate [24], edta [25], tpen [26, 27] and thioglycolate $[24,28]$, together with cys $[21,28]$. The solubility products of $\mathrm{CaCO}_{3}$ [29], $\mathrm{MgCO}_{3}$ [29], $\mathrm{Fe}(\mathrm{OH})_{2}$ [29], and $\mathrm{FeOOH}$ [7] are also given. As seen from the constants, only edta shows affinity towards $\mathrm{Mg}$ (II) and $\mathrm{Ca}$ (II) in an order resulting in serious dissolution of $\mathrm{MgCO}_{3}$ and $\mathrm{CaCO}_{3}$, whereas the remaining ligands display relatively weak binding constants, causing little dissolution of marble itself. The stability constants of cys are similar to the values of thioglycolate, and cys possess very high affinity towards iron(III), which is even higher than for edta. Towards iron(II) the overall stability constant is of an order of magnitude close to the value for tpen, thus making cys an ideal candidate for cleaning of rust stained marble.

Reduction of $\mathrm{Fe}(\mathrm{III})$ to $\mathrm{Fe}(\mathrm{II})$ by cys is accomplished by oxidation to cystine, which is insoluble in water, causing unwanted precipitation. However, the presence of SD together with cys prevents precipitation of cystine due to the ability of dithionite to re-reduce cystine formed. The reduction potential of cys is estimated to approximately $\mathrm{e}^{\prime}=-0.25 \mathrm{~V}$ at $\mathrm{pH}=7$ [22] which is higher than the potential of dithionite. In Fig. 1, the reduction reaction from cystine to cys (zwitterion form) is shown together with the acid dissociation of the thiol group, forming a cysteinate species. This anion may react as a bidentate ligand towards metal ions via the sulphur and oxygen donor atoms [22], but other coordination involving $\mathrm{O}$, $\mathrm{N}$ and $\mathrm{O}, \mathrm{N}, \mathrm{S}$ donor atoms are also possible. The ironcysteinate complexes are complicated and not straightforward due to redox reactions similar to those observed for the iron-thioglycolate system [22, 28, 30-32].

The $\mathrm{pK}_{\mathrm{a}}$ values of three functional groups i.e. carboxylic, thiol and protonated amino group are 1.88, 8.15 and 10.29 , respectively [23]. Using the values of the first two $\mathrm{pK}_{\mathrm{a}}$ constants, $\mathrm{pH}$ in solution of the cys zwitterion can

\begin{tabular}{|c|c|c|c|c|c|c|c|c|c|}
\hline \multicolumn{2}{|c|}{ Solubility products } & \multicolumn{8}{|c|}{$\beta_{n}=\left[M L_{n}\right] /[M][L]^{n} ; \beta_{n}=K_{1} \times K_{2} \times \cdots K_{n}^{a}$} \\
\hline Species & $\mathrm{K}_{\mathrm{sp}}$ & Metal ion & Citrate & Oxalate & Tartrate & EDTA & tpen & $\operatorname{tga}$ & cys \\
\hline $\mathrm{MgCO}_{3}$ & $10^{-5}$ & $M g(\|)$ & 3.4 & 4.2 & 1.4 & 8.8 & 1.7 & - & 2.7 \\
\hline $\mathrm{CaCO}_{3}$ & $10^{-8}$ & $\mathrm{Ca}(\mathrm{II})$ & 3.5 & 2.7 & 1.8 & 10.6 & 4.3 & - & 2.5 \\
\hline $\mathrm{Fe}(\mathrm{OH})_{2}$ & $10^{-14}$ & $\mathrm{Fe}(I)$ & 4.4 & 5.2 & 2.5 & 14.3 & 14.6 & 10.9 & 11.8 \\
\hline $\mathrm{FeOOH}$ & $10^{-41}$ & $\mathrm{Fe}(I I I)$ & 11.5 & 18.5 & 12.3 & 25.0 & $11^{*}$ & 32.0 & 32.7 \\
\hline
\end{tabular}
be estimated to $\mathrm{pH}$. In general this $\mathrm{pH}$ value is too low for cleaning marble, due to acid dissolution of $\mathrm{CaCO}_{3}$

Table 1 Solubility products, $K_{\text {sp, }}$ and overall stability constants, $\log \beta_{n}$, for common cleaning agents

Solubility products taken from Ref. [29], FeOOH from [7]. Overall stability constants taken from: citrate, oxalate and tartrate [24], edta [25], and tpen [26]

a The stability constant for Fe(III) is calculated from the reduction potential $\mathrm{e}^{\circ}=0.74 \mathrm{~V}$ vs SCE [27]. The values $0.98 \mathrm{~V}$ vs NHE and Fe(III)/Fe(II) $=0.77 \mathrm{~V}$ is used. Thioglycolate, tga, $\mathrm{Fe}$ (II) [24] and Fe(III) [28]. Cys, Mg(II) and Ca(II) [21], $\mathrm{Fe}$ (II) and Fe(III) [28]. The overall stability constants for Fe(II) and Fe(III)-cys refers to the biscomplexes, $\mathrm{n}=2$. For other $\mathrm{n}$-values, consult refs 


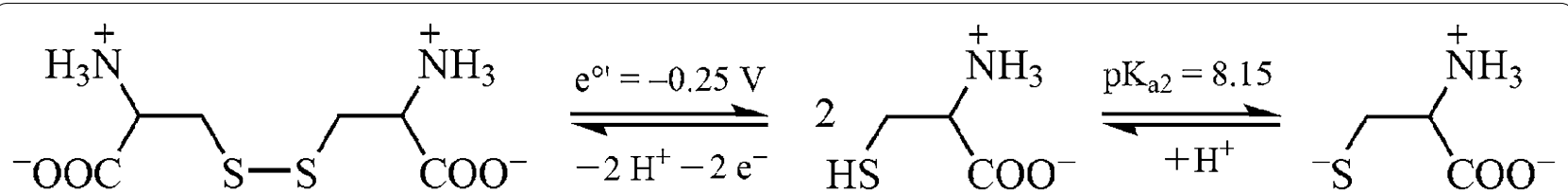

Fig. 1 Cysteine structure. Reduction reaction from cystine to cysteine and second acid dissociation constant of cysteine together with the reduction potential at $\mathrm{pH}=7$ and the $\mathrm{pK}_{\mathrm{a} 2}$ value

$[12,13]$. The $\mathrm{pH}$ value can be adjusted by the addition of a base such as ammonia $\left(\mathrm{NH}_{3}\right)$ or ammonia carbonate $\left(\left(\mathrm{NH}_{4}\right)_{2} \mathrm{CO}_{3}\right)$, and in some cases when the cleaning mixture is used in a poultice, the poultice itself can act as a buffering agent. Laponite, for example, releases $\mathrm{OH}^{-}$ below its point of zero charge, which is obtained around $\mathrm{pH}=11$ and an aqueous suspension of Laponite is alkaline [33] (measurement shows $\mathrm{pH}=9.3$ ). Since the dissolution of goethite consumes $\mathrm{H}^{+}$(Eqs. 5 and 6), the $\mathrm{pH}$ is also raised during the reaction. Considering that the oxidation of iron(II) and cys is eased with increasing $\mathrm{pH}$ favouring precipitation of both iron(III) oxyhydroxides and cystine, a reaction value around $\mathrm{pH}=7$ may be preferred, although $\mathrm{pH}=9-10$ is desired with respect to the solubility of calcite $[3,12]$.

\section{Introducing a new poultice for rust cleaning}

The chemicals used for cleaning of stained marble are commonly applied in a poultice and a wide range of poultice material has been tested and applied in stone conservation. Clay materials, such as bentonite, attapulgite and sepiolite, are widely used either alone or in combination with cellulose fibres $[4,10,34]$. Other methods use cellulose fibres alone [35, 36], MC (methyl cellulose) [37], CMC (carboxymethyl cellulose) [38], cotton pads [10,38], and gels like glycerine [10], agar [39], agarose [40], or xanthan gum [3]. One of the newer materials used for poultices is the synthetic magnesium silicate clay Laponite ${ }^{\circledR}$ RD [41-44]. When dispersed in water, Laponite produces a colourless thixotropic gel that is easy to apply on specific areas and on vertical surfaces. The high purity of Laponite and thereby the absence of natural iron impurities means that discolouration of the marble surface from the poultices itself is avoided. In this study, Laponite ${ }^{\circledR} \mathrm{RD}$ is mixed with cellulose fibres (Arbocel ${ }^{\circledR}$ BC1000) with dimensions of $700 \times 20 \mu \mathrm{m}$ (lenght and thickness) in order to increase the porosity, the absorbing properties and the water retention of the poultice. In addition to this, a small amount of sodium CMC (carboxymethyl cellulose, sodium salt) was also added. This resulted in better mechanical properties, increasing both the adherence and the cohesion of the poultice, making it easy to apply and remove in large pieces without crumbling. Another advantage of this poultice composition was its shrinkage properties: when drying it shrank practically only in the direction of thickness, leaving the area dimension intact. Hence a uniform cleaning from the centre to the edge of the poultice was obtained.

\section{Experimental \\ Samples}

Three different types of white Carrara marble (Carrara Bianco): Carrara Fabricotti, Carrara Vagli and Carrara La Piana from the Carrara quarry in Italy were received. Prior to the study and the artificial discolouration, the marble samples were characterised by the European Standards for water absorption, DS/EN 13755:2008 and water absorption coefficient by capillarity, DS/EN 1925:1999. Original samples of naturally rust stained Greenlandic marble from 1937 were retrieved from the government building of The Public Guardian in Copenhagen, Denmark in connection with restoration of the building. The marble plates were used as wall facing and, when dismounted, a heavy iron discolouration was present on the backside of the plates. A high gloss polished marble of the type Carrara Bianco, Lorano was used for etching experiments.

\section{Artificial discolouration of the samples}

Carrara samples with a size of $40 \times 10 \mathrm{~cm}$ and thicknesses of 2-4 $\mathrm{cm}$ were discoloured by immersing the samples in a $10 \% \mathrm{w} / \mathrm{w} \mathrm{FeCl}_{2}$ solution for 1 month. The samples were then dried at ambient temperature, cut into pieces of $10 \times 4 \mathrm{~cm}$, and finally dried in an oven at $60{ }^{\circ} \mathrm{C}$ for 4 days. For cleaning in solution, pieces were further cut into smaller parts at $4 \times 2 \mathrm{~cm}$.

\section{Cross sections of samples}

Cross sections were prepared by embedding samples in epoxy resin, cutting the samples to a thickness of $1 \mathrm{~cm}$, followed by grinding.

\section{Microscopy}

Cross sections were analyzed by Zeiss Axioplan 2 polarisation microscope. 


\section{pH measurement}

$\mathrm{pH}$ values were measured with a Radiometer PHM240

$\mathrm{pH} /$ ionmeter calibrated at $\mathrm{pH}=7$ and $\mathrm{pH}=10$.

\section{Cleaning experiments}

All experiments were performed at ambient temperature and RH. In order to investigate and optimize the chemical composition of the cleaning agents alone, samples of the discoloured coarse porosity marble La Piana were immersed in $100 \mathrm{~mL}$ of four different solutions all being $0.1 \mathrm{M}$ of each chemicals: 1 cys, 2 cys $+\mathrm{SD}, 3$ cys $+\left(\mathrm{NH}_{4}\right)_{2} \mathrm{CO}_{3}$, and 4 cys $+\mathrm{SD}+\left(\mathrm{NH}_{4}\right)_{2} \mathrm{CO}_{3}$, respectively. All solutions were contained in crystallization beakers and placed on magnetic stirrers, which were stirred slowly for $24 \mathrm{~h}$ at ambient temperature. After $24 \mathrm{~h}$ the samples were retrieved, rinsed with water and dried.

Based on the results from the solution experiments, iron removal was investigated with the cleaning agents mixed in poultices. In these experiments samples of the three different Carrara marble types and of the naturally rust stained Greenlandic marble were used. The ratio of the poultice materials was Laponite ${ }^{\circledR} \mathrm{RD} /$ Arbocel $^{\circledR} \mathrm{BC} 1000 / \mathrm{CMC} / \mathrm{H}_{2} \mathrm{O}=10: 10: 1: 86$. For cleaning of an area of ca. $10 \mathrm{~cm}^{2}$, the following recipe was used: $0.52 \mathrm{~g}$ of L-cysteine $(4.29 \mathrm{mmol})$ was dissolved in $43 \mathrm{~mL}$ of tap water by stirring and after complete dissolution $0.75 \mathrm{~g}$ of $\mathrm{Na}_{2} \mathrm{~S}_{2} \mathrm{O}_{4}(4.31 \mathrm{mmol})$ was added. The solution was then added with stirring to a $250 \mathrm{~mL}$ beaker containing a blend of $5 \mathrm{~g}$ Laponite, $5 \mathrm{~g}$ Arbocel and $0.5 \mathrm{~g}$ CMC. For the poultice containing ammonium carbonate, an additional $0.41 \mathrm{~g}(4.27 \mathrm{mmol})$ of $\left(\mathrm{NH}_{4}\right)_{2} \mathrm{CO}_{3}$ was added to the cys $+\mathrm{SD}$ solution. The poultice containing ammonia used a $0.2 \mathrm{M} \mathrm{NH}_{3}$ solution instead of water.

The $\mathrm{pH}$ value of the mixed poultices was measured to be $\mathrm{pH} 6.8$ for cys $+\mathrm{SD}$, $\mathrm{pH} 7.8$ for cys $+\mathrm{SD}+\left(\mathrm{NH}_{4}\right)_{2} \mathrm{CO}_{3}$, and $\mathrm{pH} 10.1$ for cys $+\mathrm{SD}+\mathrm{NH}_{3}$. The poultice was applied in a layer of $1-1.5 \mathrm{~cm}$ thickness, covered with polyethylene food wrap, and left for $24 \mathrm{~h}$. The plastic film was then removed and the sample was left overnight to dry the poultice. The poultice was then removed, the sample rinsed with water and dried in air.

The optimized method was finally applied in situ on a larger area $(74 \times 58 \mathrm{~cm})$ of The Marble Church in Copenhagen, Denmark. The lower part of the church is built in Norwegian Gjellebekk marble, which has unstable forms of pyrite and shows rust stains due to pyrite oxidation. The poultice containing $0.1 \mathrm{M}$ cys $+0.1 \mathrm{M}$ SD was applied on the church in a thickness of approximately $0.5 \mathrm{~cm}$, covered with plastic and left overnight. The plastic was then removed and the poultice allowed to dry for additional $24 \mathrm{~h}$ before removal, where after the surface was finally washed with water.

\section{Results and discussion}

In Table 2 the result from the porosity measurements, water absorption, and water absorption coefficient by capillarity is seen. This classifies the porosity of the Carrara marble types as fine, medium and coarse, which is Fabricotti, Vagli and La Piana, respectively.

Microscopy of discoloured Carrara samples shows the discolouration as small orange crystals in grain boundaries in homogenously distributed between the calcite crystals in the entire sample. Higher concentrations are observed in internal cracks and bigger pores in the stone. In the Greenlandic marble the discolouration is only detected on the surface of the sample. The presence of pyrite was confirmed in all the samples of Carrara marble as black cubic isotropic minerals. In the artificially discoloured samples, the formation of akaganeite, $\beta-\mathrm{FeOOH}$, could be argued, as this crystal form is the one formed in the presence of chloride ions [6], whereas goethite, being the most stable rust species, is likely found in the naturally discoloured samples [9]. Further identification of the iron compounds was not possible by microscopy due to the very small crystal size of the rust particles.

The visual result from the cleaning experiments with solution 1, 2, 3 and 4 is shown in Fig. 2 as a, b, c, and d, respectively. A section of the artificially discoloured marble piece before cutting into smaller samples is shown at the top of Fig. 2. As seen in Fig. 2b, d, the samples from solution 2 and 4 containing both cys and SD are visually most cleaned. The cleaning effect in solution 2 and 4 was observed already after $1 \mathrm{~h}$, and at that time no effect was observed in solution 1 and 3 . In solution 1 and 3 , a white precipitate identified as cystine by ATR-FTIR and XRD (see Additional files 1, 2, 3) was observed after 3 and $1.5 \mathrm{~h}$, respectively. Leaving the solution 2 and 4 exposed to air after retrieving the sample, cystine precipitation was seen after 48 and $24 \mathrm{~h}$, respectively. These observations indicate the importance of dithionite with respect to both the kinetically reduction and dissolution of rust as well as the prevention of the cysteine oxidation. The faster precipitation in solution 1 and 3, also shows the acceleration of cys oxidation in basic solution. Along

$\begin{aligned} & \text { Table } 2 \text { Porosity } \\
& \text { marbles }\end{aligned}$
\begin{tabular}{lll} 
Marble type & $\begin{array}{l}\text { Water } \\
\text { absorption } \mathbf{A}_{\mathbf{s}}(\%)\end{array}$ & $\begin{array}{l}\text { Capillarity } \mathbf{C}_{\text {mean }} \\
\left(\mathbf{g} / \mathbf{m}^{\mathbf{2}} \mathbf{s}^{\mathbf{0 . 5}}\right)\end{array}$ \\
\hline Carrara Fabricotti & 10.99 & 1.41 \\
Carrara Vagli & 12.82 & 5.05 \\
Carrara La Piana & 36.76 & 7.28
\end{tabular}

Characterization of the porosity of three marble types by European standards. Water absorption by immersion in water at atmospheric pressure, DS/EN 13755:2008, and water absorption coefficient by capillarity, DS/EN 1925:1999 

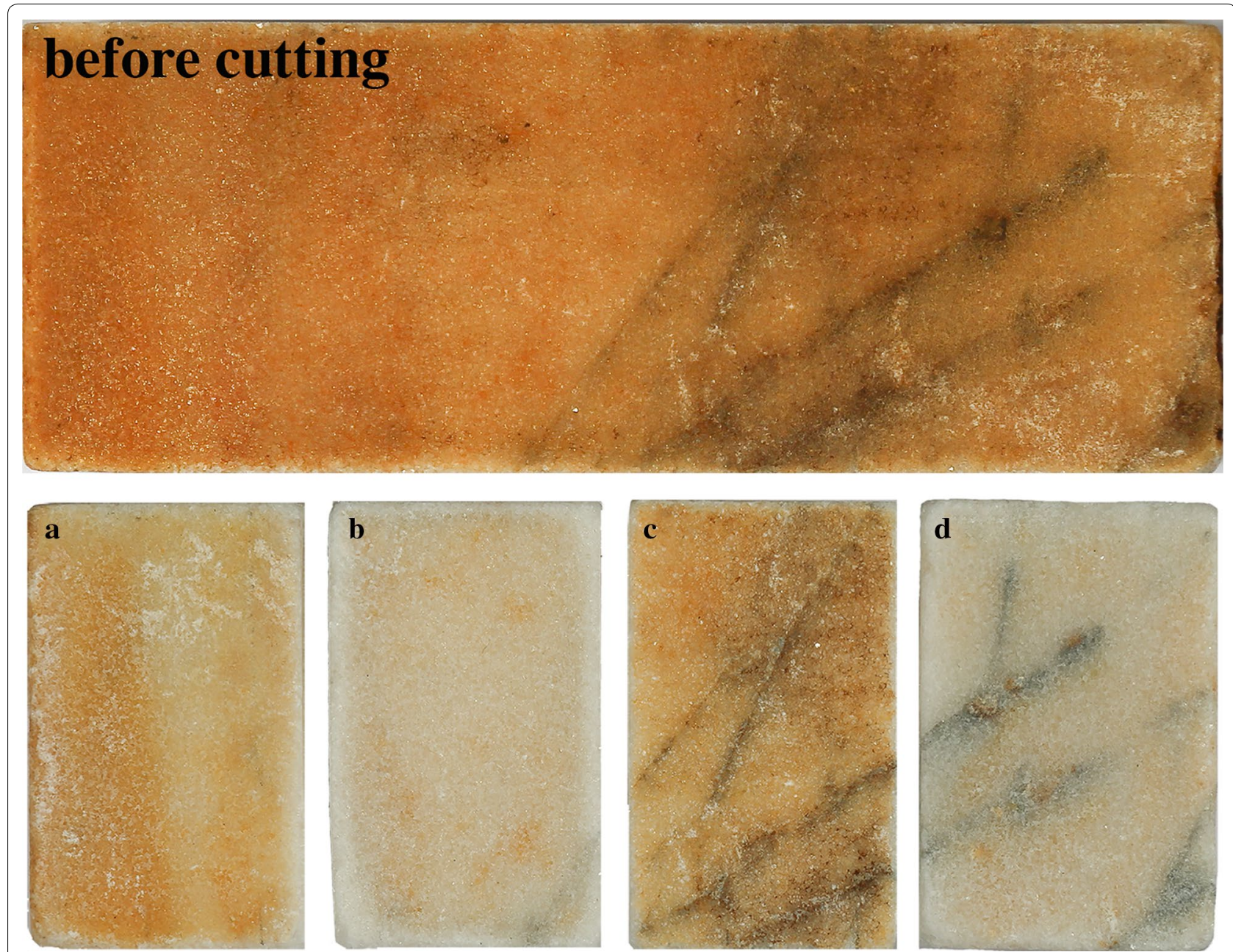

Fig. 2 Cleaning in solution. Result of cleaning experiments from immersion of samples $(4 \times 2 \mathrm{~cm})$ of artificially discoloured La Piana Carrara marble in $0.1 \mathrm{M}$ solutions of $\mathbf{a}$ cys, $\mathbf{b}$ cys $+\mathrm{SD}, \mathbf{c} \mathrm{cys}+\left(\mathrm{NH}_{4}\right)_{2} \mathrm{CO}_{3}, \mathbf{d}$ cys $+\mathrm{SD}+\left(\mathrm{NH}_{4}\right)_{2} \mathrm{CO}_{3}$. The artificially discoloured marble piece $(10 \times 4 \mathrm{~cm})$ before cutting into smaller parts is shown at the top of the figure

with the cystine precipitation, the colour of the solutions turned bluish, indicating oxidation of Fe(II) to Fe(III) and the formation of Fe(III)-cys complexes [22, 28].

$\left(\mathrm{NH}_{4}\right)_{2} \mathrm{CO}_{3}$ was used as a buffer agent to obtain an alkaline $\mathrm{pH}$ value in order to investigate any difference in etching of the marble surface. Using $\mathrm{pK}_{\mathrm{a}}=9.25$ for the ammonium ion and $\mathrm{pK}_{\mathrm{a} 2}=8.18$ for the cysteine thiol group, $\mathrm{pH}$ can be estimated to $\mathrm{pH}=1 / 2$ $(8.18+9.25)=8.7$ in solutions 3 and 4 , whereas $\mathrm{pH}$ in solutions 1 and 2 is estimated to $\mathrm{pH} 5$ for the zwitterion of cys. However, based on visual observation of the roughness, the samples in Fig. 2 did not show any difference concerning etching of the surface with respect to presence of the buffer. Therefore, this issue was further investigated in the poultice cleaning experiments as well as in an experiment on high gloss polished marble.
Based on the solution results, cleaning experiments were performed with poultices containing a mixture of either cys + SD alone or with addition of a buffer of $\left(\mathrm{NH}_{4}\right)_{2} \mathrm{CO}_{3}$ or of $\mathrm{NH}_{3}$. The poultices were applied on all three types of Carrara marble, and the visual results of the experiments with cys $+\mathrm{SD}$ and cys $+\mathrm{SD}+\left(\mathrm{NH}_{4}\right)_{2} \mathrm{CO}_{3}$ are shown in Fig. 3. The three types of marble: Fabricotti (a), Vagli (b) and La Piana (c), are shown from left to right. The top section of each sample is cleaned with the poultice containing $\left(\mathrm{NH}_{4}\right)_{2} \mathrm{CO}_{3}$, whereas the bottom is cleaned with the poultice bearing cys $+\mathrm{SD}$ only. The middle section shows the discolouration before cleaning.

As seen in Fig. 3, a difference in the cleaning effectiveness, depending on the marble type, can be observed. The difference reflects the water absorption and the capillarity of the marble as well as the coarse porosity type. La 


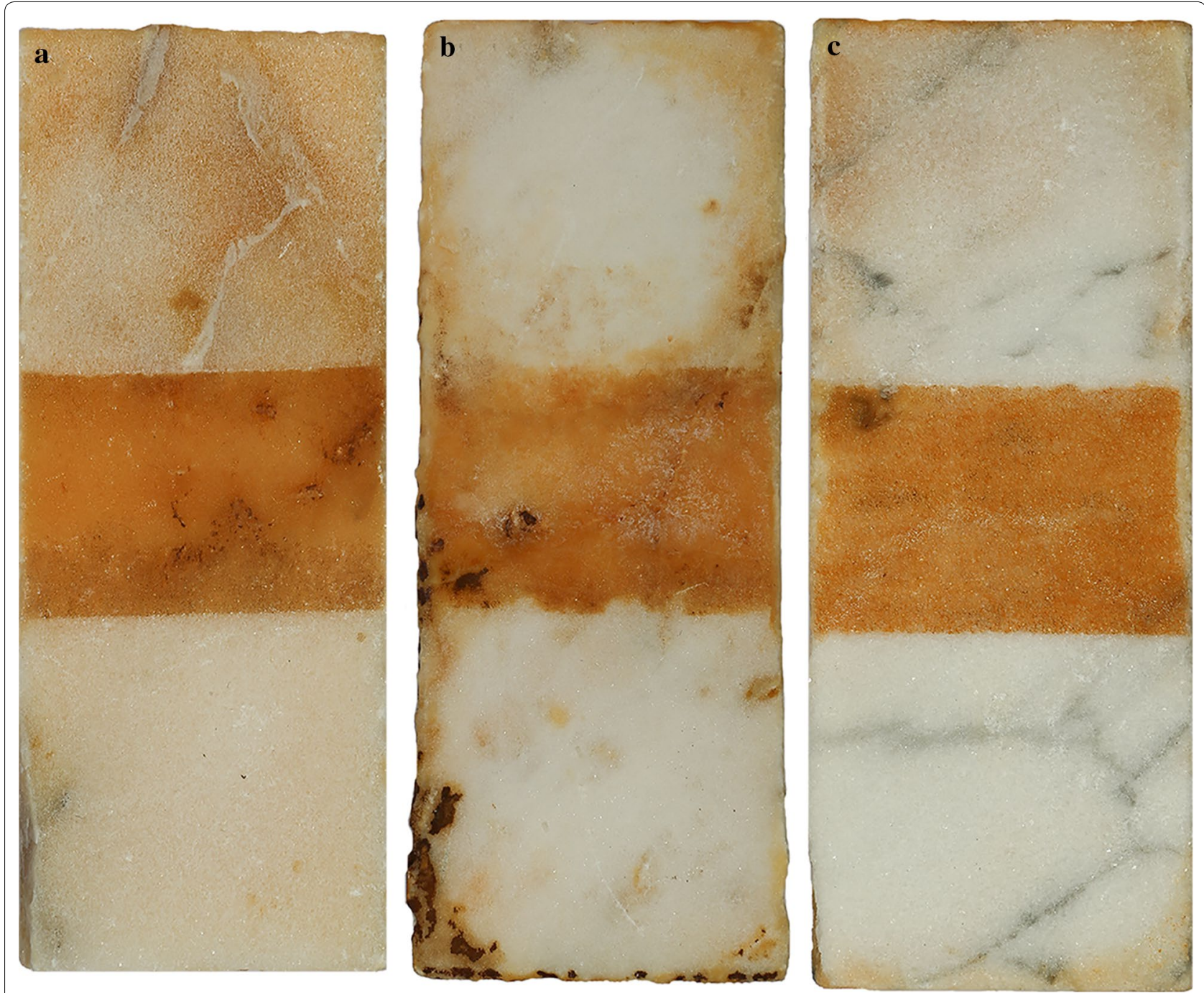

Fig. 3 Cleaning with poultice. Result of cleaning experiment with two different poultices on the three different types of Carrara marble. a Fabricotti, b Vaglia, c La Piana. Top polutice with cys + SD + $\left(\mathrm{NH}_{4}\right)_{2} \mathrm{CO}_{3}$. Bottom poultice with cys + SD only. Concentration of each chemical $0.1 \mathrm{M}$. The middle fields show the uncleaned area. Sample size $10 \times 4 \mathrm{~cm}$

Piana is visually the most efficiently cleaned sample. This result is confirmed by cross sections of the three cleaned samples (Fig. 4). A difference in effectiveness owing to the presence of $\left(\mathrm{NH}_{4}\right)_{2} \mathrm{CO}_{3}$ can also observed in the individual samples. These sections are less cleaned compared to the sections without $\left(\mathrm{NH}_{4}\right)_{2} \mathrm{CO}_{3}$. In addition to the lower cleaning effect, the poultice containing $\left(\mathrm{NH}_{4}\right)_{2} \mathrm{CO}_{3}$ also showed changes in its mechanical behaviour and, upon removal, the poultice was crumbling.

The result using $\mathrm{NH}_{3}$ as buffer (not shown) is similar to $\left(\mathrm{NH}_{4}\right)_{2} \mathrm{CO}_{3}$. The samples are less cleaned, however, the poultice did not show tendency of crumbling. This result may indicate an increased oxidation of cys to cystine in basic solution, hence lowering the amount of cys able to react with iron(II). This result could also imply that the crumbling of the poultice arises from the salt concentration of $\left(\mathrm{NH}_{4}\right)_{2} \mathrm{CO}_{3}$ rather than the basicity.

Figure 4 shows the photographs of parts of the cross sections of the marble types Fabricotti (a), Vagli (b) and La Piana (c) cleaned with the poultice containing cys + SD only. As seen in Fig. 4, the difference in the cleaning effect reflects the porosity of the sample. All samples are cleaned on the surface. Fabricotti and Vagli shows no discolouration in the top $0.4 \mathrm{~mm}$, whereas La Piana is cleaned at twice the depth, showing no discolouration in the top $0.8 \mathrm{~mm}$. As also seen in Fig. 4, no poultice material is observed on the surface of the samples, indicating the coherence of the poultice and its ease 


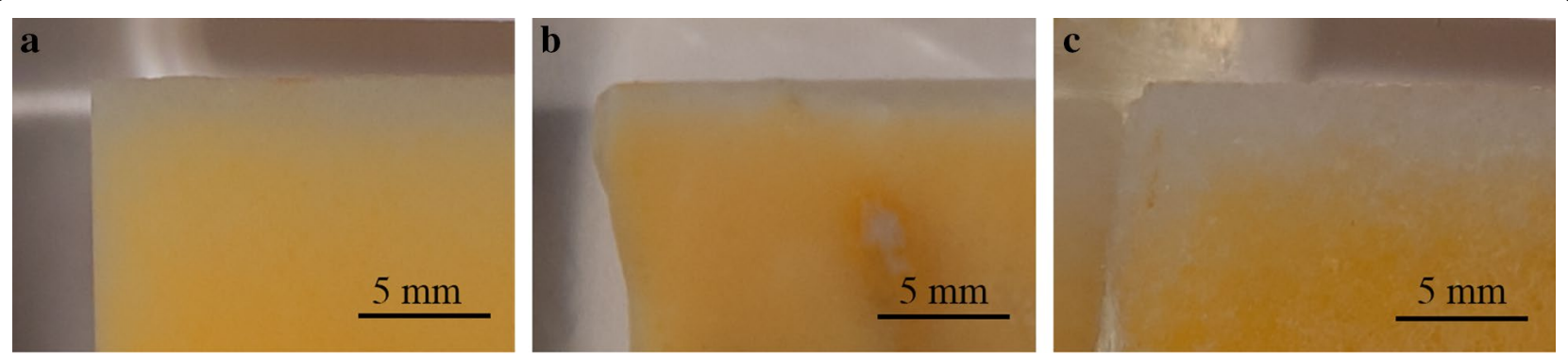

Fig. 4 Cross sections. Enlarged parts of the cross sections of the three different types of Carrara marble showing the cleaning depth after cleaning with a poultice containing 0.1 M cys + 0.1 M SD. a Fabricotti, b Vaglia, c La Piana

of removal after cleaning. By comparing the backside of the samples with the treated surfaces, no further etching of the surface could be detected apart from the etching already introduced by the artificial discolouration.

Figure 5 shows the cleaning experiment of a sample of naturally stained Greenlandic marble with the poultice containing cys and SD only. After one treatment, the surface was cleaned satisfactorily. The right part of the photograph shows the poultice material after cleaning and the yellowing of the poultice material reflects the absorbed iron.

Figure 6 shows the in situ experiment on The Marble Church in Copenhagen. The rust stained area due to

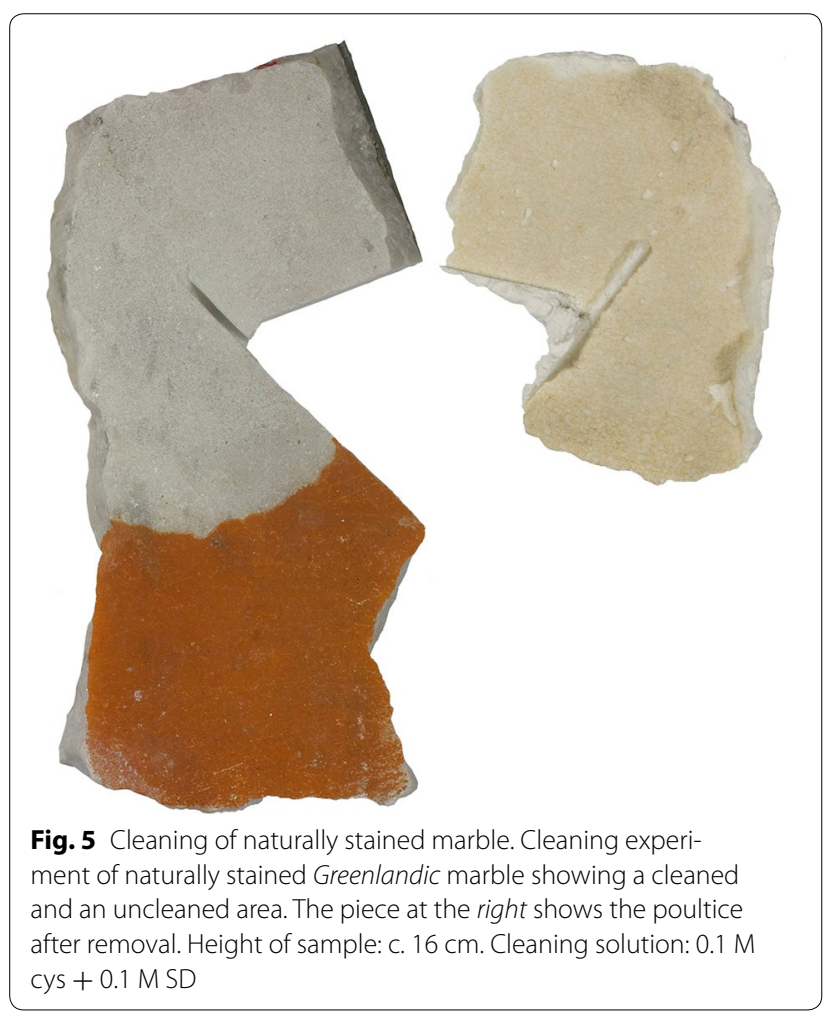

pyrite oxidation before cleaning is seen in Fig. 6a, the area covered with the poultice in Fig. $6 \mathrm{~b}$, and the area after cleaning in Fig. 6c. The rust layer was removed after one treatment, leaving a cleaned surface without rust stains. The blackish shades still observed after cleaning are likely to be pyrite or other impurities still present in the underlying pores in the stone.

To further investigate any etching of the marble by the chemical cleaning formulations and the poultice itself, mixtures with cys + SD alone, with the additional buffers $\left(\mathrm{NH}_{4}\right)_{2} \mathrm{CO}_{3}$ and $\mathrm{NH}_{3}$, and the poultice prepared with water only, were applied on high gloss polished marble of the type Carrara Bianco, Lorano. The result shows, based on visual observation of roughness, that a slight etching had occurred with the chemical cleaning formulation while no etching was observed with the poultice alone. The etching with cys $+\mathrm{SD}$ alone was slightly worse compared to the formulations with $\left(\mathrm{NH}_{4}\right)_{2} \mathrm{CO}_{3}$ and $\mathrm{NH}_{3}$, whereas with $\mathrm{NH}_{3}$ the etching was almost invisible. This indicates the $\mathrm{pH}$ effect on the marble stone and that cys + SD does show a weak complexation and solubilization of the marble. However, the etching was only in the order of few micrometres and was only visually observable on high gloss polished marble. Based on these results, the use of the cysteine-dithionite formulation should be avoided on high polished marble. However, for marble used in outdoor environments already having a naturally weathered surface, the consequence and importance of this slight etching is debatable.

\section{Conclusion}

Cleaning of rust stained marble by the use of cys and SD as cleaning agents in a Laponite ${ }^{\circledR} \mathrm{RD}$ poultice has been investigated. The cleaning system was developed on artificially discoloured samples of Carrara marble and tested on samples of naturally rust stained Greenlandic marble and in situ on a larger area on The Marble Church in Copenhagen, Denmark. 

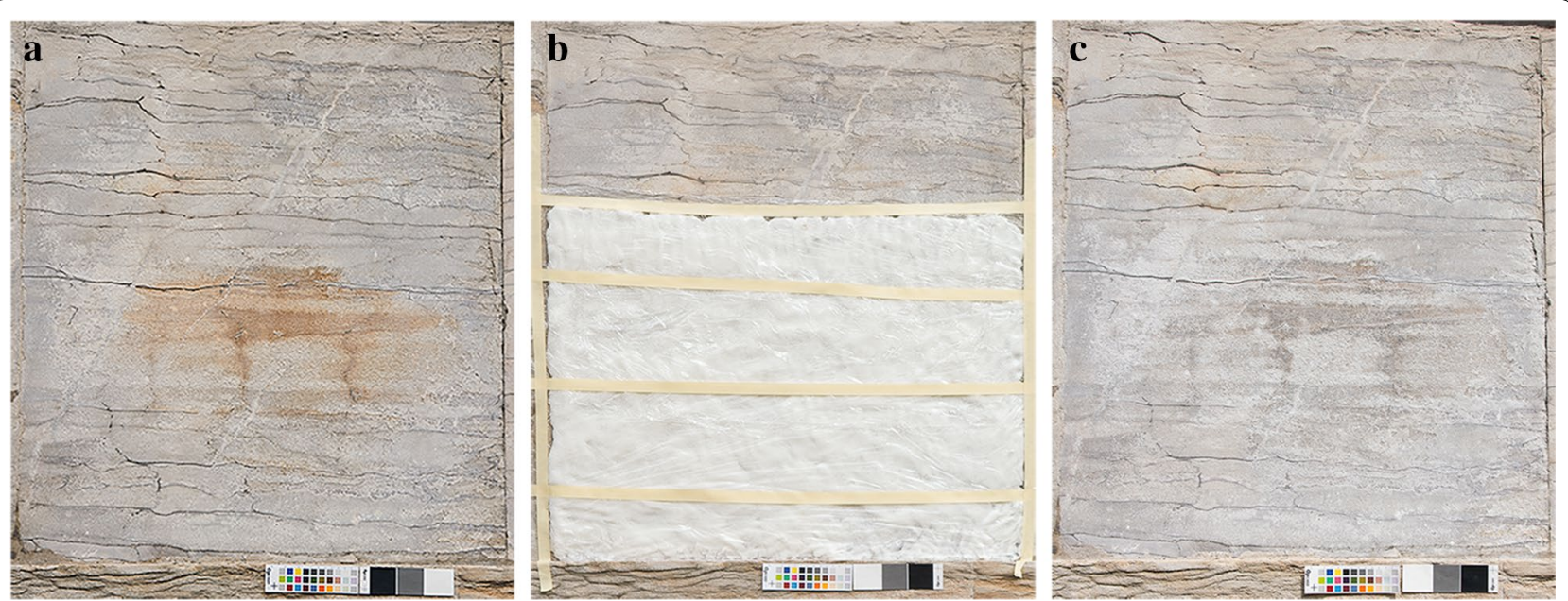

Fig. 6 Photograps of in situ cleaning. Photographs of the cleaning experiments on the Marble Church in Copenhagen. $\mathbf{a}$ before cleaning, $\mathbf{b}$ the applied poultice, $\mathbf{c}$ after removal of the poultice. Area of poultice $74 \times 58 \mathrm{~cm}$. Cleaning solution: $0.1 \mathrm{M}$ cys $+0.1 \mathrm{M} \mathrm{SD}$

The Laponite was mixed with cellulose fibres with dimensions of $700 \times 20 \mu \mathrm{m}$ (Arbocel ${ }^{\circledR}$ BC1000) in order to increase the porosity, the absorbing properties and the water retention of the poultice. A small amount of sodium CMC was added to optimize the rheological and mechanical properties. The poultice adhered well to marble and its cohesion strength made it possible to remove in large pieces without crumbling and no residual poultice was left on the marble. When drying, the poultice only shrank in the direction of thickness, giving a uniform cleaning of the covered area.

The use of SD gives a kinetically fast reduction of $\mathrm{FeOOH}$ to iron(II), which forms strong coordination complexes with cys. The complexes are absorbed into the poultice material and a cleaned marble surface is obtained in a short time. A slight etching in order of few micrometres of the surface can be observed on high gloss polished marble. However, the consequence and pragmatic importance of this can be discussed when cleaning marble showing wear and tear such as wall facings, pedestals, fountains or staircases.

The cleaning procedure developed is a simple do-ityourself method. The shelf life of the mixed poultice is approximately $2-4 \mathrm{~h}$ depending on the temperature. However, a relatively short shelf life is expected when strong reducing agents able to reduce rust are used. This means that a larger amount of premixed poultice can be prepared in the laboratory or studio and brought to the worksite, or the poultice can be mixed on-site needing only water and the solid compounds.

The ratio of the poultice materials is Laponite ${ }^{\circledR} \mathrm{RD} /$ Arbocel ${ }^{\circledR} \mathrm{BC} 1000 / \mathrm{CMC} / \mathrm{H}_{2} \mathrm{O}=10: 10: 1: 86$ and the concentrations of both cys and SD is $0.1 \mathrm{M}$. For cleaning an area of ca. $100 \mathrm{~cm}^{2}$ the following recipe can be used: $5.2 \mathrm{~g}$ of L-cysteine $(43 \mathrm{mmol})$ is dissolved in $430 \mathrm{~mL}$ of tap water by stirring and after complete dissolution $7.5 \mathrm{~g}$ of $\mathrm{Na}_{2} \mathrm{~S}_{2} \mathrm{O}_{4}$ (43 mmol) is added. The solution is added with stirring to a $2 \mathrm{~L}$ beaker containing a blend of $50 \mathrm{~g}$ Laponite, $50 \mathrm{~g}$ Arbocel and $5 \mathrm{~g}$ CMC. Before applying the poultice, the area is cleaned by wet-brushing in order to remove soluble deposits and salts. This wetting also gives a better adherence of the poultice. The wet poultice is applied on the marble surface in a layer being $1-1.5 \mathrm{~cm}$ in thickness, covered with polyethylene food wrap, and left for $24 \mathrm{~h}$. The plastic film is removed and the poultice is left overnight for drying and then removed and disposed in accordance with national regulation. The marble surface is finally rinsed with water.

\section{Additional files}

Additional file 1: Fig S1. ATR-FTIR spectrum of the white precipitate. The ATR-FTIR spectrum of the white precipitate identifies it as cystine.

Additional file 2: Fig S2. XRD pattern of the white precipiate and of cystine. The white precipitate is identified as cystine by comparison of their XRD patterns.

Additional file 3. Supplementary material for: Effective cleaning of rust stained marble.

\section{Authors' contributions}

All authors contributed to data interpretation and to finalizing the manuscript. All authors have read and approved the final manuscript.

\section{Author details}

${ }^{1}$ School of Conservation, Esplanaden 34, 1263 Copenhagen K, Denmark. ${ }^{2}$ Department of Chemistry, Faculty of Science, Okayama University, Okayama 700-8530, Japan. ${ }^{3}$ Department of Chemistry, University of Copenhagen, Universitetsparken 5, 2100 Copenhagen $\varnothing$, Denmark. 


\section{Acknowledgements}

The authors would like to thank The Scandinavia-Japan Sasakawa Foundation, The Okayama University International Exchange Scholarship, and The Danish Chemical Society Travel Foundation for making first authors research stay in Okayama, Japan possible. Finally, we thank Maya Coulson for critically reviewing the text.

\section{Competing interests}

The authors declare that they have no competing interests.

Received: 1 October 2015 Accepted: 13 April 2016

Published online: 05 May 2016

\section{References}

1. Pinna D, Galeotti M, Rizzo A. Brownish alterations on the marble statues in the church of Orsanmichele in Florence: what is their origin? Herit Sci. 2015;3:7.

2. Bams $V$, Dewaele $S$. Staining of white marble. Mater Charact. 2007;58:1052-62.

3. Cushman M, Wolbers R. A new approach to cleaning iron stained marble surfaces. WAAC Newsletter. 2007;29:23-8.

4. Macchia A, Sammartino MP, Tabasso ML. A new method to remove copper corrosion stains from stone surfaces. J Archaeol Sci. 2011;38:1300-7.

5. Hœrlé S, Mazaudier F, Dillmann P, Santarini G. Advances in understanding atmospheric corrosion of iron. II. Mechanistic modelling of wet-dry cycles. Corros Sci. 2004;46:1431-65.

6. Dillmann P, Mazaudier F, Hœrlé S. Advances in understanding atmospheric corrosion of iron. I. Rust characterisation of ancient ferrous artefacts exposed to indoor atmospheric corrosion. Corros Sci. 2004;46:1401-29

7. Cudennec $Y$, Lecerf $A$. The transformation of ferrihydrite into goethite or hematite, revisited. J Solid State Chem. 2006;179:716-22.

8. Yu J-Y, Park M, Kim J. Solubilities of synthetic schwertmannite and ferrihydrite. Geochem J. 2002;36:119-32.

9. Majzlan J, Navrotsky A, Schwertmann U. Thermodynamics of iron oxides: part III. Enthalpies of formation and stability of ferrihydrite $\left(\mathrm{Fe}(\mathrm{OH})_{3}\right)$, schwertmannite $\left(\mathrm{FeO}(\mathrm{OH})_{3 / 4}(\mathrm{SO} 4)_{1 / 8}\right)$, and $\varepsilon-\mathrm{Fe}_{2} \mathrm{O}_{3}$. Geochim Cosmochim Acta. 2004;68:1049-59.

10. Stambolov T. Removal of iron stains from calcareous stone. Stud Conserv. 1968:13:45-7

11. Matero FG, Tagle AA. Cleaning, iron stain removal, and surface repair of architectural marble and crystalline limestone: the metropolitan club. J Amer Inst Conserv. 1995;34:49-68.

12. Thorn A. Treatment of heavily iron-stained limestone and marble sculpture. In: Verger I, James J, editors. ICOM Committee for Conservation 14th Triennial Meeting, vol. 2. Copenhagen: ICOM Publications; 2005. p. 888-94.

13. Gervais C, Grissom CA, Little N, Wachowiak MJ. Cleaning marble with ammonium citrate. Stud Conserv. 2010;55:164-76.

14. Rueda EH, Ballesteros MJ, Grassi RL. Dithionite as a dissolving reagent for goethite in the presence of EDTA and citrate. Application to soil analysis. Clays Clay Miner. 1992;40:575-85.

15. Varadachari C, Goswami G, Ghosh K. Dissolution of iron oxides. Clay Res. 2006;25:1-22

16. Irwin S. A comparison of the use of sodium metabisulfite and sodium dithionite for removing rust stains from paper. In: Gilligan E, editor. The book and paper group annual, vol. 30. Columbia: American Institute for Conservation of Historic and Artistic Works; 2011. p. 37-46.

17. Selwyn L, Tse S. The chemistry of sodium dithionite and its use in conservation. Stud Conserv. 2008;53:61-73.

18. Mayhew SG. The redox potential of dithionite and $\mathrm{SO}_{2}{ }^{-}$from equilibrium reactions with flavodoxins, methyl viologen and hydrogen plus hydrogenase. Eur J Biochem. 1978:85:535-47.

19. Ohlsson P-I, Blanck J, Ruckpaul K. Reduction of lactoperoxidase by the dithionite anion monomer. Eur J Biochem. 1986;158:451-4.
20. Roden EE. Fe(III) oxide reactivity toward biological versus chemical reduction. Environ Sci Technol. 2003;37:1319-24.

21. Berthon G. Critical evaluation of the stability constants of metal complexes of amino acids with polar side chains (technical report). Pure Appl Chem. 1995:67:1117-240.

22. Sisley MJ, Jordan RB. Kinetic and equilibrium studies of the reactions of cysteine and penicillamine with aqueous iron(iii). Inorg Chem. 1995;34:6015-23

23. Amirbahman A, Sigg L. Gunten UV: reductive dissolution of fe(III) (hydr) oxides by cysteine: kinetics and mechanism. J Colloid Interface Sci. 1997;194:194-206.

24. Martell AE, Smith RM. Critical stability constants: other organic ligands, vol. 3. New York: Plenum Press; 1977.

25. Martell AE, Smith RM. Critical stability constants: amino acids, vol. 1. New York: Plenum Press; 1974.

26. Shumaker DK, Vann LR, Goldberg MW, Allen TD, Wilson KL. TPEN, a Zn ${ }^{2+}$ / $\mathrm{Fe}^{2+}$ chelator with low affinity for $\mathrm{Ca}^{2+}$, inhibits lamin assembly, destabilizes nuclear architecture and may independently protect nuclei from apoptosis in vitro. Cell Calcium. 1998;23:151-64.

27. Segaud N, AnxolabehereMallart E, SenechalDavid K, AcostaRueda L, Robert M, Banse F. Electrochemical study of a nonheme Fe(II) complex in the presence of dioxygen. Insights into the reductive activation of $\mathrm{O}_{2}$ at Fe(II) centers. Chem Sci. 2015;6:639-47.

28. Tanaka N, Kolthoff IM, Stricks W. Iron-cysteinate complexes. J Am Chem Soc. 1955;77:1996-2004.

29. CRC. Handbook of chemistry and physics. 55th ed. Cleveland: CRC Press; 1974.

30. Bhattacharyya A, Stavitski E, Dvorak J, Martínez CE. Redox interactions between Fe and cysteine: spectroscopic studies and multiplet calculations. Geochim Cosmochim Acta. 2013;122:89-100.

31. Leussing DL, Kolthoff IM. Iron-thioglycolate complexes. J Am Chem Soc. 1953;75:3904-11.

32. Balocchio C, Mentasti E, Arselli P. Kinetics and mechanisms of complex formation and redox reactions of iron(III) with mercaptocarboxylic ligands in acid perchlorate media. Transition Met Chem. 1983;8:6.

33. Jatav S, Joshi YM. Chemical stability of Laponite in aqueous media. Appl Clay Sci. 2014;97-98:72-7.

34. Alessandrini G, Dassú G, Bugini R, Formica L. The technical examination and conservation of the portal of St. Aquilino's Chapel in the Basilica of St. Lorenzo, Milan. Stud Conserv. 1984:29:161-71.

35. Vergès-Belmin $V$, Heritage $A$, Bourgès A. Powdered cellulose poultices in stone and wall painting conservation - myths and realities. Stud Conserv. 2011;56:281-97.

36. Uğuryol M. The conservation of the mosaic of the "house of the ionic capitals" in Hierapolis (Pamukkale, Turkey). J Cult Herit. 2013;14:e125-32.

37. Lauffenburger JA, Grissom CA, Charola AE. Changes in gloss of marble surfaces as a result of methylcell ulose poulticing. Stud Conserv. 1992;37:155-64.

38. El-Gohary M. Experimental tests used for treatment of red weathering crusts in disintegrated granite-Egypt. J Cult Herit. 2009;10:471-9.

39. Gulotta D, Saviello D, Gherardi F, Toniolo L, Anzani M, Rabbolini A Goidanich S. Setup of a sustainable indoor cleaning methodology for the sculpted stone surfaces of the Duomo of Milan. Herit Sci. 2014:2:1-13.

40. Warda J, Brückle I, Bezúr A, Kushel D. Analysis of agarose, carbopol, and laponite gel poultices in paper conservation. J Amer Inst Conserv. 2007;46:263-79.

41. Lee L-M, Rogers P, Oakley V Navarro J. Investigations into the use of laponite as a poulticing material in ceramics conservation. VA Conser J. 1997;22:9-11.

42. da Silveira L. A note on the poultice cleaning of feathers using Laponite RD gel. Stud Conserv. 1997:42:11-6.

43. Rozeik $C$. The treatment of an unbaked mud statue from ancient Egypt. J Amer Inst Conserv. 2009;48:69-81

44. Garland KM, Twilley J. The restoration, treatment, scientific examination, and re-treatment of an Egyptian limestone relief from the Tomb of Kaaper. J Amer Res Cent Egypt. 2009:45:303-17. 